\title{
A solidariedade como elemento constitutivo da res publica
}

\section{Solidarity as an element establishing of res publica}

\author{
Jose Luis Bolzan de Morais ${ }^{1}$ \\ Guilherme Camargo Massaú ${ }^{2}$
}

\section{Resumo}

O texto objetiva estabelecer a solidariedade como mecanismo de acesso à república, não apenas como um elemento político, mas como elemento estrutural da realização em coletividade dos aspectos individuais e sociais próprios do ser humano. A abertura está na possibilidade de deixar de ser um coadjuvante eleitor temporalmente requisitado para se constituir em ator cotidianamente participativo na construção do mundo próprio e comum, diretamente relacionada à solidariedade internacional.

Palavras-chave: Coabitação. Homem. Internacional. Sociedade. Solidariedade.

\section{Abstract}

The text aims to establish solidarity as a mechanism for access to the republic, not only as a political element, but as a structural element in the realization of collective individual and social aspects of human beings themselves. The opening is on the possibility of ceasing to be a voter supporting temporally ordered to be constituted in every day participatory actor in building the world of its own common, directly related to international solidarity.

Keywords: Cohabitation. Man. International. Society. Solidarity.

\footnotetext{
1 Professor do PPGD/UNISINOS e Procurador do Estado do Rio Grande do Sul. Pesquisador do CNPq.

2 Doutor em Direito pela UNISINOS (bolsista Capes/Prosup). Mestre em Filosofia do Direito pela Universidade de Coimbra.
} 


\section{Introdução}

Os valores inerentes ao republicanismo fornecem mecanismos na direção do aprimoramento da democracia ${ }^{3}$ que, inserida neste contexto, invoca os cidadãos a contribuírem com a formação da sociedade e a manutenção do mundo para as gerações futuras. Porém, esta intervenção do cidadão - de forma adequada - no mundo-da-vida (Lebenswelt) só pode ser efetuada diante do máximo proveito da tríade revolucionária francesa - liberte, egalité, fraternité.

Destarte, a república, como forma de governo e maximizadora da liberdade - aspecto jurídico -, pode fundamentar a liberdade ao comprometer-se, incontornavelmente, com a dignidade humana, sendo o Estado Constitucional a sua ossatura.

$\mathrm{Na}$ república, a obrigatoriedade da lei (Direito) ou da ordem jurídica, a vontade de todos os cidadãos, também se expressa no costume, tendo o parlamentar (legislador), o funcionário público, o juiz [...] a necessidade de observá-la a fim de cumprirem suas funções, seja na representação do povo $^{4}$, seja por outra fonte de legitimação democrática. Sem a atenção ao direito costumeiro, a res publica não pode ser res populi, pois o costume, como liberdade interna, pressupõe o direito à autonomia, como a liberdade externa. Con tudo, a República reúne em uma identidade a liberdade, a juridicidade e a estatalidade ${ }^{5}$.

No âmago republicano, o preponderante será a inter-relação entre os socii, na perspectiva da prática, no sentido de construir e manter a res publica para a usufruição, em condições dignas, da vida individual. Nisto insere-se a solidariedade como um elemento de ação e

3 AGRA, Walber de Moura. Republicanismo. Porto Alegre: Livraria do Advogado, 2005, p. 12.

4 Não se pode esquecer o fundamento jurídico da representação: Art. $1^{\circ}$, parágrafo único, da CF.

5 SCHACHTSCHNEIDER, Karl Albrecht. Res publica res populi. Grundlegung einer Allgemeinen Republiklehre. Ein Beitrag zur Freiheits-, Rechts - und Staatslehre. Berlin: Duncker \& Humblot, 1994, p. VII. 
de ligação prática entre os socii, capaz de interferir na dinâmica liberal ou comunitarista sem polarizar no indivíduo nem na comunidade. Isto preserva as duas dimensões existentes no ser humano: o ser único e o ser social.

A solidariedade como abertura tem por objetivo incluir na cosmovisão republicana o elemento prático da razão, no sentido de orientar a ação humana no seio da coletividade. A res publica fornece as precondições normativas para a realização da solidariedade, ou seja, um sistema jurídico, contendo liberdade e igualdade, que possa instituir o vínculo solidário entre as pessoas ${ }^{6}$.

Ela assume, também, a tentativa de tornar real a fraternité, do lema revolucionário francês, e tenta amenizar a atual dinâmica individualista, que faz preponderar a liberdade e a igualdade dos indivíduos nas reflexões sociais atuais.

É necessária uma nova relação entre os indivíduos, uns com os outros. Assim, resta a fraternité ${ }^{7}$ como projeto revolucionário. Se, por um lado, conhece-se ${ }^{8}$ a liberté, e, por outro, a égalité ${ }^{9}$, a fraternité ${ }^{10}$ não possui uma aplicação político-social e jurídica reconhecida e assentada. A questão encontra-se no fato da fraternité não ser um Direito (algo normatizado), mas um princípio moral, capaz somente de obrigar nesta esfera.

ZOLL, Rainer. Was ist Solidarität heute? Frankfurt am Main: Suhrkamp, 2000, p. 140-141.

ZOLL, Was ist Solidarität heute? p. 38 e 39.

8 Conhecer, no sentido empregado, indica a possibilidade de dizer, ao utilizar-se das diversas correntes, o que é ou não a liberdade e a igualdade, porém a fraternidade (aqui será empregada o termo solidariedade) ainda encontra-se explorada, pelo menos no âmbito politicojurídico.

9 A liberdade e a igualdade possuem vastas bibliografias que as dissecam, opostamente à fraternidade que, em comparação as duas, não tem as atenções voltadas a si. DELOGU, Antonio. Repubblica e civiche virtù. In: Lezioni per la repubblica. La festa è tornata in città. A cura di Maurizio Viroli. Reggio Emilia: Diabasis, 2001, p. 48.

10 PIAZOLO, Michael. Solidarität. Deutungen zu einem Leitprinzip der Europäischen Union. Würzburg: Ergon, 2004, p. 13. 
Adespeito da liberdade e da igualdade só a fraternité, ressignificada para solidarité, é capaz de conduzir o indivíduo da coletividade (de um aglomerado de indivíduos) para o da sociedade (um conjunto ordenado de pessoas com reconhecimento mútuo), logo, de criar uma vida comum calcada numa ética solidária, capaz de produzir um crescimento de dignidade na medida em que o eu investe suas capacidades na promoção do outro. E isto é válido para todas as relações intersubjetivas, assim como para as interinstitucionais e as inter-estatais. Nesta direção é justamente este o elemento capaz de unir as distintas culturas do mundo numa cosmópolis, a reconhecer os direitos fundamentais/ humanos, a liberdade, a igualdade e a justiça ${ }^{11}$.

Estas palavras só possuem significado quando inseridas no contexto social ao relacionar, pelo menos, dois ou mais indivíduos. Sem este pressuposto nenhuma delas possui sentido, por conseguinte, recai a relação intersubjetiva e junto interpelam-se os respectivos significados no ambiente sociocultural. Inclui-se a república, é justamente no seu seio que se operará a interação entre os socii.

Tal significa, em primeira instância, que na República as interrelações devem constituir-se de acordo com o princípio republicano e de todas as consequências que este possa acarretar ao mundo-da-vida.

11 DELOGU, Repubblica e civiche virtù. p. 48. Por meio disto pode se fortalecer a idéia de paz política - que não significa a ausência de conflito. A questão da paz como a paz política possui dois sentidos, um estreito e um amplo. O primeiro concentra-se na ação política dentro das prioridades da paz. O segundo está em todas as ações, que as condições de possibilidade da paz devem produzir e apoiar. A paz só é possível por meio da conduta humana. Ela precisa da verdade, ela não se apresenta na fantasia, mas na vida. Para isso cada Homem precisa ajudar na formação da paz, por meio da luta pela verdade. Este combate é pacífico a resolver-se pela luz de uma primeira suspeita de verdade. $O$ medo é o receio fundado diante da própria incapacidade para a paz, e a resolução do conflito sem paz aproxima sua falta de paz do medo. VON WEIZSÄCKER, Carl Friedrich. Der Garten des Menschlichen. Beiträge zur geschichtlichen Anthropologie. Müchen/Wien: Carl Hanser, 1977, p. 42-43. 
Por derradeiro, tenta-se constituir um agir adequado à realidade da res publica, por isto, a necessidade da distinção entre privado e público. Somente nesta última esfera os reflexos republicanos terão relevância, muito embora, na esfera privada existam direitos e deveres indisponíveis - fundamentalmente os referentes aos que afetam a dignidade humana -, transportando-os para o âmbito ou força público(a).

Objetivamos por em evidência uma perspectiva republicana envolvida pela solidariedade, devido ao fato de compreender a dinâmica solidária como apta a constituir um ambiente propício à divisão de um mesmo mundo por inúmeras subjetividades sem a submissão de nenhuma individualidade. Assim como é urgente, hoje em dia, usufruir deste mundo sem destruir o meio ambiente, mantendo-o para as futuras gerações. Tanto a coabitação quanto a manutenção do meio ambiente são atos que envolvem a solidariedade e que alertam para uma coisa pública.

A fim de estabelecer a dinâmica solidária na res publica é necessário salientar essa dinâmica como característica do ser humano, pois somente ele possui a capacidade de solidariedade enquanto serque determina os seus atos. Destarte, como ele compõe seu próprio mundoda-vida, ele se enveredou num caminho de globalização/mundialização em que todos os espaços do mundo encontram-se interligados e sofrem mútua influência. Por isso a necessidade de invocar a solidariedade estatal internacional, pois não se vive isolado num espaço, mas interligado com espaços. O representante, no âmbito internacional, das realidades e dos interesses especificamente regionais é o Estado, o que resulta na solidariedade interestatal.

Em suma, a discussão aqui posta pretende salientar a inclusão da solidariedade na res publica e busca contribuir para uma melhor compreensão de tais pressupostos, todos presentes no constitucionalismo contemporâneo, tomado este não apenas como expressão legislativa de um contrato social particular, mas como projeto cultural compartilhado civilizatoriamente, inclusive no brasileiro. 


\section{A problemática fundamental a ser enfrentada - a coabitação num mesmo mundo}

A dramaticidade da questão republicana encontra-se entre o nascimento e a morte do indivíduo. Esta realidade humana não Ihe é opção, mas imposição - não lhe é permitido escolher o seu vir ou não à existência -, por consequência, o Homem é lançado no mundo ${ }^{12}$ que, de imediato, Ihe exige assumir a responsabilidade de ter nascido e de ter decido viver ${ }^{13}$. O viver é propriamente uma tarefa, a mais complexa praticada pelo Homem, pois ele é, ao mesmo tempo, o artista e o objeto de sua arte, estando aí inerente, inclusive, o desejo do suicídio ou o abandonar a vida ${ }^{14}$.

Este Dasein no mundo impõe a responsabilidade de fazer-se a si mesmo. No início o mundo não é amigável nem hostil, o indivíduo liberto (com o nascimento) não possui outra opção a não ser habitá-lo e dar-lhe um sentido ao se adaptar ao e constituir o mundo - num mundo-da-vida - e a si próprio ${ }^{15}$. Nisto encontra-se o desafio de lidar com a duplicidade humana, no sentido de reconhecê-lo, sofocletianamente, a maravilha das maravilhas que inesperadamente se move entre o bem e o mal ${ }^{16}$.

Em princípio, esta é a tônica da liberdade nos âmbitos privado e público. Após a percepção de si mesmo o indivíduo é confrontado com um mundo-da-vida já historicamente constituído (que possui o seu próprio sentido), sem a sua interferência e, além do mais, se apercebe da existência do outro. O outro interpela o eu na sua radical diferença, na mesma medida da existência liberta do eu existe o outro livre, tanto

12 FAZERES, António. Esboço de uma fenomenologia da liberdade. Phainomenon, Lisboa, n. 1, 2000, p. 63 e ORTEGA Y GASSET, José. O homem e a gente. Inter-comunicação humana. Trad. J. Carlos Lisboa. 2. ed. Rio de Janeiro: Livro Ibero-Americano, 1973, p. 81.

13 FAZERES, Esboço de uma fenomenologia da liberdade. Phainomenon, p. 68.

14 FROMM, Erich. Análise do homem. Trad. Octavio Alves Velho. 9. ed. Rio de Janeiro: Zahar, 1974, p. 25-26.

15 FAZERES, Esboço de uma fenomenologia da liberdade. Phainomenon, p. 63.

16 SÓFOCLES. Antígona. Trad. Donaldo Schüler. Porto Alegre: L\&PM, 2006, p. 28 e 30. 
quanto o eu, o que o diferencia de outras espécies de animais. O que lhe concede posição privilegiada no mundo ${ }^{17}$.

A partir do autocontrole ${ }^{18}$ de se ensimesmar ${ }^{19}$, o eu recolhe-se ao seu íntimo pensamento e pode agir de forma irretocavelmente única. Isto situa o eu como um ser único e irrepetível na história - diferente das demais espécies -, na medida em que sua realidade radical (o íntimo) não pode ser totalmente compreendida por ninguém, somente pelo próprio eu. A vida pessoal é intransferível na totalidade ao outro, porém pode ser apreendida por meio da interpretação da exteriorização de sinais do eu. Neste momento, a impossibilidade de assumir a vida intimista de outrem revela o fundamento da responsabilidade pessoal. Assim, o que afeta ao eu pode não afetar ao outro ${ }^{20}$.

Com o surgimento da consciência do ser-estar-aí-no-mundo, o eu jogado num ambiente - com sua tradição - preexistente (família, cidade, escola [...]), se vê legitimado a realizar a própria vontade que faz do eu mesmo objeto de suas ações, numa condição prática de reconhecimento do próprio Direito no(s) outro(s) ${ }^{21}$.

Contudo, na toada da ética humanista é possível inferir o Homem como entidade original, diferente das demais, inclusive ele como indivíduo e compartilhando as qualidades essenciais com os demais membros da mesma espécie, ele destoa em sua mistura particular ao apresentar caráter, temperamento, talentos, habilidades, características físicas

17 ORTEGA Y GASSET. O homem e a gente, p. 109-130.

18 A questão do autocontrole é desenvolvida por ELIAS, no sentido de atribuir o progresso civilizatório ao aumento do autocontrole. Destarte, o Estado moderno entra nesta perspectiva no momento de considerá-lo um ente fruto do progressivo aperfeiçoamento deste autocontrole. Assim, também se inclui o Homem moderno com suas personalidades adaptadas à complexidade das relações intersubjetivas dentro do ambiente estatal, ou seja, na esfera pública. Isto tem conexão com a tolerância ao diferente em todos os aspectos, o que não ocorria em sociedades ou comunidades mais arcaicas. Nesse sentido e em outros, vide ELIAS, Norbert. O processo civilizador. Formação do estado e civilização. Trad. Ruy Jungmann. v. 2. Rio de Janeiro: Jorge Zahar, 1993, p. 193-274.

19 Vide ORTEGA Y GASSET. O homem e a gente, p. 57-62.

20 ORTEGA Y GASSET. O homem e a gente, p. 77-94.

21 JELLAMO, Anna. Interpretazione del bene comune. Saggio su Thomas H. Green. Milano: Giuffrè, 1993, p. 40 (nota 81). 
distintas (genótipo e fenótipo, por exemplo: as impressões digitais) [...]. Tal pensamento ético distingue o bem do mal ao defender que o primeiro é afirmação da vida no sentido desenvolvimentista das capacidades do Homem; a virtù decorre na assunção da responsabilidade de sua própria vida22. O vício é o contrário do bem, ele consiste na redução das capacidades do Homem, sendo o vício a irresponsabilidade diante de si mesmo. Portanto, o conhecimento do Homem é alicerce para o edifício de normas e de valores ${ }^{23}$.

Pode-se designar a tudo isto como parte integrante da vita activa ${ }^{24}$. Nela desenvolvem-se três atividades essenciais ao ser humano: labor, trabalho e ação. Cada uma corresponde o suporte básico da vida humana. O labor (nascimento, sobrevivência e morte) está ligado ao processo biológico do corpo, por conseguinte, o crescimento, o metabolismo e o declínio estão relacionados com as atividades produzidas pelo labor no processo vital. Com isto, a condição humana do labor corresponde à própria vida. O trabalho (artefato, produto ou coisa que proporcionam durabilidade, permanência ao caráter mortal e efêmero do humano)

22 O que se poderia afirmar, parafraseando ALIGHIERI, com todas as implicações decorrentes é que a nossa paz está na nossa vontade ("E está na Sua vontade a nossa paz."). ALIGHIERI, Dante. Divina Comédia. Paraíso. Trad. Italo Eugenio Mauro. São Paulo: 34, 1998 (Canto III, verso 85), p. 28.

23 FROMM, Análise do homem, p. 27-28 e 31. Com isto, e ainda na esteira do "parafraseamento" de ALIGHIERI, não se pode permitir que o próprio Homem, portanto o nós, o pórtico de sua própria casa (o Welt) com o abandono de toda a esperança daqueles que nele ingressam ("Deixai toda a esperança, ó vós que entrais."). ALIGHIERI, Dante. Divina Comédia. Inferno. Trad. Italo Eugenio Mauro. São Paulo: 34, 1998 (Canto III, verso 9), p. 37.

24 ARENDT discorre sobre o termo vita activa e nela está todo o peso da tradição ocidental do pensamento político. Esta tradição não abrange a totalidade do pensamento ocidental, mas carrega em si o julgamento de Sócrates e conflito entre a polis e os filósofos, ainda foi utilizada com cuidado por KARL MARX. Esta expressão foi tradução medieval do bios politikos aristotélico e que ocorre em AGOSTINHO como vita negotiosa ou actuosa. Seu significado estava relacionado com os assuntos públicos e, por conseguinte políticos. Cabe destacar a fuga da concepção tradicional vita activa arendtiana, pois a vita activa deve ficar acima nem abaixo da vita contemplativa na hierarquia do conhecimento. ARENDT, Hannah. A condição humana. Trad. Roberto Raposo. 10. ed. Rio de Janeiro: Forense Universitária, 2003, p. 20-26. Ver, ainda, BOLZAN DE MORAIS, José Luis. A subjetividade do tempo. Perspectivas transdisciplinares do direito e da democracia. Porto Alegre: Livraria do Advogado. 1996. 
relaciona-se ao aspecto artificial da vida humana. Ele produz um mundo diferente de qualquer ambiente natural, sendo que nele reside cada vida solitária-individual. As coisas advindas do trabalho possuem características transcendentes à vida individual, tendo o trabalho como condição humana a mundanidade. A ação (cria as condições de fundar e preservar os corpos políticos além de proporcionar as condições para a história) é exercida entre os seres humanos e não tem a mediação das coisas - da matéria -, por conseguinte, nela encontra-se a pluralidade. É a pluralidade de Homens e não um único que habita o mundo. Isto implica ter, necessariamente, relação com a política, cuja função é estabelecer os parâmetros da coexistência plural. Assim, viver é estar entre os seres humanos e, morrer é abandoná-los ${ }^{25}$.

Estas três atividades fundamentais devem ser respeitadas e promovidas no mundo-da-vida - que é o mundo da ação e do trabalho onde o labor atua de forma segura (em tese). A aparição do outro impele o eu a comungar com o diferente o mesmo e único mundo. Este comungar com o outro significa a aparição do nós. A junção de duas ou mais realidades radicais distintas num ambiente preexistente e repleto de pluralidade humana, justamente no nós reside o aristotelismo do zoón politikón. Nota-se, com isto, que o eu depende do outro para compreender o seu próprio mundo-da-vida, desde sempre aí, e para sobreviver, simultaneamente em que se faz a si mesmo, inovando-se. Se em face à realidade radical o eu detém a plena liberdade - sendo os seus limites as fronteiras intransponíveis do próprio eu -, em face à realidade coexistencial com o outro no nós, a sua liberdade não é mais plena, mas restrita. A coabitação exige do eu o reconhecimento do outro (com sua liberdade) e a adequação ao nós e ao mundo-da-vida. Portanto, encontra-se a liberdade (no seu aspecto público) delimitada pela liberdade do outro e pelas normas socioculturais. A coexistência de pluralidades humanas, ou seja, interesses de vida distintos, num único espaço, ocasionam o conflito entre os indivíduos ${ }^{26}$.

\footnotetext{
25 ARENDT, A condição humana, p. 15-16.

26 Vide FROMM, Análise do homem, p. 46
} 
O ponto crítico da República - no aspecto político-jurídico - é justamente a divisão da unidade mundanal entre as liberdades dos seres humanos, a fim de viabilizar-lhes o melhor ambiente possível para que cada um possa desenvolver-se plena e dignamente conforme os seus desejos e os seus interesses, com o mínimo de conflito com o outro.

A divisão deste único mundo não pode ser efetuada de forma negativa, ou seja, a existência da liberdade de cada indivíduo de maneira isolada, cada qual independente dos demais. A incontornável característica de ser social não permite a vida em pleno isolamento, pelo contrário, obriga o indivíduo manter relações com os seus pares (a partir do nascimento até a morte) - desde o âmbito privado (família, amigos, associações privadas...) até o âmbito público (órgãos públicos, na rua com desconhecidos...). O Homem é só e, simultaneamente, relacionado com o(s) outro(s). Esta ambivalência se manifesta na solidão e na comunhão, na igualdade e na diferença. Por conseguinte, a solidão indica seu caráter original, inautêntico ao outro e consciente de ser independente, no entanto, ele não suporta a completa ruptura dos seus semelhantes, uma vez que sua felicidade (ou vida) está atrelada à inter-relação vivenciada com os outros, seja de gerações passadas, presentes e futuras ${ }^{27}$.

É preciso reconhecer dois aspectos simultâneos de um mesmo ser humano: sua individualidade e sua sociabilidade ${ }^{28}$. A liberdade permeia estas duas peculiaridades humanas, pois é justamente ela que viabiliza o desenvolvimento, a usufruição e a realização de cada indivíduo consigo mesmo; a segunda é complemento da primeira, além

27 FROMM, Análise do homem, p. 46.

28 Estes dois aspectos estão no fundamento da discussão entre os liberais e os comunitaristas. A discussão entre essas correntes políticas iniciou por volta do início da década de oitenta do século XX nos Estados Unidos da América. Nela concentra-se a relação do indivíduo e da comunidade, um tema discutido há séculos. Trata-se, no fundo, da conturbada polarização que de um lado está uma política democrática de reivindicação de direitos individuais e de liberdade e do outro, está a consideração do bem comum - numa perspectiva de absorver e restringir ao máximo a liberdade e direitos individuais. Vide o contraposto entre estas duas visões de mundo em relação à solidariedade. Vide PIAZOLO, Solidarität, p. 112-128. 
de ser condição de possibilidade da própria vida individual - o eu não é sem o outro (e aqui surge a importância da comunicação) ${ }^{29}$.

Portanto, são duas dinâmicas que se complementam e, também, se contrapõem. O desafio é justamente equilibrar esta polaridade de forças entre o individua ${ }^{30}$ e o social de tal forma que ambos possam se complementar sem conflitos extremos. Em face disto, a solidariedade possui a dinâmica apropriada para intermediar ao unir o indivíduo (liberdade) e o sócio (igualdade) ${ }^{31}$ ou, ainda, a igualdade e a diferença. A diferença se constitui quando o eu estranha o outro justamente pelas características ímpares deste outro, a igualdade é o reconhecimento do outro como ser igual ao eu, ser humano ${ }^{32}$.

\section{O Homem e as outras espécies no mesmo meio-ambiente}

A solidariedade não é delimitada apenas pela reciprocidade direta entre Homem-Homem, mas também em relação às outras espécies de animais e ao meio-ambiente, pois o mundo da cultura no qual o ser

JASPERS, Karl. Iniciação filosófica. Trad. Manuela Pinto dos Santos. 6. ed. Lisboa: Guimarães \& Cia. s.d., p. 26.

30 Reconhece-se hoje em dia a preponderância do individual sobre o social, isto se denomina individualismo.

31 Destaca-se, imiscuído nas ponderações de FROMM, que a igualdade tornou-se a negação da individualidade. A igualdade não é considerada mais a condição para o desenvolvimento das particularidades de cada ser humano, mas a ausência do eu de orientação mercantil. Se antes a igualdade poderia ser associada à diferença, neste momento ela tornou-se sinônimo de indiferença, nada além da característica do Homem consigo e com o outro. Este pensamento acarretou diversas transformações em todas as áreas da cultura e todas elas as refletem a personalidade mercantil de ser livre, inclusive de qualquer individualidade. FROMM, Análise do homem, p. 71 e 74 . A revisão da República busca contornar a concepção mercantil da igualdade, ao abrir caminho à alternativa humana de escolher a sua própria estrada. A questão não é reprimir a maldade e enaltecer a bondade, mas potencializar em tornar as pessoas virtuosas ao criar as condições para o desenvolvimento de cada pessoa, como meta de todas as atividades sociais, econômicas, políticas e jurídicas em que o ser humano seja a única finalidade para si mesmo. Isto convoca a regra de ouro: não façais aos outros o que não quereis que vos façam ou, ainda, o que fizeres aos outros faça também a si mesmo. FROMM, Análise do homem, p. 191 e 194.

32 ZOLL, Was ist Solidarität heute? p. 165. 
humano se insere encontra-se rodeado por um meio-ambiente natural fornecedor dos elementos necessários (vitais) para a existência humana com dignidade.

No entanto, a solidariedade Homem-demais espécies e meio ambiente tem como último destinatário o próprio Homem, embora esteja, neste caso, diretamente ligada às espécies e ao meio ambiente indiretamente ela atinge os seres humanos. Deve-se isto ao caráter ético da solidariedade, logo, o Homem se coloca como o centro do universo no sentido dos seus julgamentos de valores, intimamente arraigados às peculiaridades de sua própria existência.

Nestas circunstâncias, como querem alguns, o ser humano se apresenta como e é tido como a medida de todas as coisas (PROTÁGORAS). Tal postura origina-se de uma ética humanista antropocêntrica ${ }^{33}$. Porém, não deve significar uma posição de soberba em relação aos demais elementos constituintes do Planeta Terra, pelo contrário, isto lança diretamente a responsabilidade sobre cada ser humano.

A (r)evolução científica - de forte impulso no iluminismo equipou o Homem de conhecimentos em relação a vastos domínios da biodiversidade. Ele tornou-se capaz de manipular a essência genética, de domesticar, de multiplicar e de extinguir as espécies vegetais e animais. Desta forma, ocorreu um desencantamento da natureza, transformando-a em simples objeto econômico para construir seus sonhos, uma natureza domesticada a serviço das finalidades humanas, em particular como objeto de suas pretensões capitalísitcas.

De um meio-ambiente selvagem para um completamente domesticado, porém, o ser humano não se deu conta que o impulso natural não é mau nem bom, ele apenas segue seu destino naturalmente imanente. Mas o ser humano é capaz, atualmente, de destruir a habitabilidade da Terra, sob a justificação de domar o meio-ambiente

33 FROMM, Análise do homem, p. 22. 
natural. No entanto, esta domesticação do habitat não humano provoca consequências imprevistas e de grandes proporções à própria condição humana.

O desenvolvimento acarretou o esquecimento das dificuldades vividas pelos antepassados quanto ao domínio dos eventos naturais ao mesmo tempo em que, pelo domínio da natureza, criou desequilíbrios fomentadores de resultados inimagináveis até o momento. Portanto, não são os movimentos naturais - que seguem seu rumo sem serem ruins ou bons para o ser humano -, mas a atitude de intervenção do Homem na natureza a causar o desequilíbrio ambiental, por conseguinte, a deterioração do habitat humano ${ }^{34}$.

Em face disto, é o ser humano, o único responsável. Ele se constitui em perigo para si e para os demais seres humanos, da sua e das futuras gerações, do seu território e dos demais cantos do mundo, assim como para todos os demais seres e para o próprio ambiente natural e, mesmo, aquele construído. Ele deve adotar uma postura entre a estática contemplação e a exploração brutal, ou seja, uma atitude de respeito e colaboração com o meio ambiente ${ }^{35}$, ora explorando e ora restituindo, em equivalência, o explorado. A sua capacidade de extração pode e deve ser convertida para uma capacidade de restituição.

A conservação do meio-ambiente é de interesse público mundial, destarte, o meio-ambiente se constitui em patrimônio público mundial e tal se constitui em ação e ideia compatíveis com a República. Não significa dotar os animais nem o meio ambiente de direitos, pois os animais ou o ecossistema como um todo são incapazes de criar um mundo paralelo como o Homem, como a cultura ${ }^{36}$, por meio da liberdade.

34 ELIAS, Norbert. A condição humana. Trad. Manuel Loureiro. Lisboa: Difel, 1991, p. 15-25.

35 NOGARE, Pedro Dalle. Humanismo e anti-humanismo. Introdução à antropologia filosófica. 12. ed. Petrópolis: Vozes, 1990, p. 233.

36 A aparição da espécie humana ocasionou consequências como seu agir sobre o mundo físico, sobre as outras espécies e sobre si mesmo. A partir de então o Homem "hominiza" o Planeta Terra ao perfazer a sua sempre inacabada natureza. COMPARATO, Fábio Konder. A afirmação histórica dos direitos humanos. 2. ed. São Paulo: Saraiva, 2001, p. 6. 
A eles são destinadas proteções jurídicas que vinculam todos os Homens. Não existe a relação entre direito do animal ou vegetal com o dever humano, nem direito humano e dever do animal e/ou vegetal, com isto, a reciprocidade inerente de direito-dever é violada, desqualificando de direito dos animais e/ou vegetais para proteção contra a ação degradante humana ${ }^{37}$.

Portanto, a responsabilidade de manter o equilíbrio no ecossistema e de não maltratar os animais concentra-se no próprio ser humano. Ela é consequência do direito-e-dever dos socii e, atualmente se destaca, das gerações futuras de terem um ambiente saudável-equilibrado.

Diante de tudo isto, não se deseja negar a ligação do Homem com a natureza, pelo contrário, é justamente esta profunda conexão ${ }^{38}$ que é ressaltada na questão preservacionista. A manutenção do ecossistema é a própria preservação humana, pois sem ele a vida se extinguiria.

Porém, é preciso destacar o descontinuum das espécies com o Homem. Este ser supera os demais animais na medida em que transcende a sua própria natureza ou instinto, e seu espírito o diferencia de todos os demais seres vivos. O Homem é um ser eterno por ser mortal e viver de forma individual cuja história é identificável no período que compreende do nascimento à morte; sua eternidade dá-se justamente com a cessação da vida única e intransferível. Já as demais espécies encaixam-se na imortalidade por meio da procriação e suas vidas não são identificáveis pela história, elas são repetições instintivas da vida dos seus ancestrais ${ }^{39}$, ou seja, não existe vida individual. Neste sentido, o animal não parte de si mesmo, mas está sempre condicionado ao que se passa ao seu redor, ou seja, não possui a capacidade de se ensimesmar ${ }^{40}$.

37 Não se deseja desqualificar as teorias jurídicas que adotam a diretriz oposta, porém, para efeito deste trabalho, se adotará esta concepção teórica. Não só, também por não observar consistência nestas teorias. No entanto, esta discussão não cabe no objetivo deste trabalho.

38 NOGARE. Humanismo e anti-humanismo, p. 231.

39 ARENDT. A condição humana, p. 27.

40 ORTEGA Y GASSET. O homem e a gente, p. 56-57. 
A radicalidade humana é a liberdade cuja expressão se forma em um movimento espiralado. Isto ocorre em três etapas: na primeira o Homem se encontra perdido no mundo entre as coisas, na segunda o seu esforço de formação da ideia e domínio sobre estas coisas - a contemplação ou a vita contemplativa - recolhido em sua intimidade e, na terceira, o Homem retorna ao mundo com o intuito de atuar nele conforme o plano preconcebido (ou concebendo) - a práxis ou a vita activa $^{41}$.

$\mathrm{Na}$ vita activa surge e se concretiza a solidariedade, portanto, ela está relacionada somente aos seres humanos e entre eles se realiza. A solidariedade deve ser um conceito condutor universal com o objetivo de reivindicar uma sociedade solidária ${ }^{42}$, porém a solidariedade não pressupõe a reciprocidade, presente ou futura, mas a partir da interpelação no momento oportuno. A sua prática, em princípio, deve ser desinteressada. Precisa ser concretizada pela prática reflexiva entre os "parceiros" sociais e não por meio de uma submissão de quem recebe a solidariedade e de quem é solidário. Seria um processo de observação e aplicação da ação solidária ${ }^{43}$.

\section{A solidariedade: o Homem como ser social}

O princípio da solidariedade esta sustentado na natureza do Homem, pois ele constitui sua natureza, com isso sua identidade. Ela existirá enquanto existir o Homem, este é o fundamento da tese do ser humano como ser social.

41 ORTEGA Y GASSET. O homem e a gente, p. 62.

42 PIAZOLO. Solidarität, p. 13.

43 Destarte, o Homem solidário como pressuposto de uma sociedade solidária precisa adquirir uma competência social, capaz de se autoperceber e de perceber o estranho, banhado na capacidade de aceitar o outro e a si mesmo. Isto por meio do encontro com o outro e consigo mesmo intermediado por comunicação como um constante processo de aprendizado. ZOLL, Was ist Solidarität heute? p. 113-114. 
O Homem não sobrevive sozinho, ele se encontra na companhia do outro e numa comunidade em geral organizada, por isso, não é um ser só, mas social (comunitário). Ele é instruído para viver no mundo por meio da ajuda do outro, em face disto quem não precisa da sociedade é Deus (ou deuses) ou animal ${ }^{44}$. A conexão entre solidariedade e pessoa está na relação eu e outro.

A pessoa surge na mutualidade do encontro, pois se depara e se desenvolve com o outro, mesmo mantendo a individualidade. $\mathrm{O}$ eu experiencia-se como eu em unidade com o eu-outro, codeterminandose reciprocamente. $O$ grande exemplo desta coexistência é a linguagem que só pode ser constituída quando existir a interpelação recíproca entre dois indivíduos. Isto é um processo que se inicia ao nascer e somente se extingue com a morte. Durante o período entre estes dois acontecimentos intermediado pelo emprego linguístico ergue-se o relacionamento comunitário e disto resulta a cultura e a história ${ }^{45}$.

A série de valores éticos como a justiça, a confiança, o amor, ou a gratidão possui sentido se pensados conjuntamente com o outro ou com os muitos. Assim, tais valores estimulam o Homem à sociedade. $\mathrm{Na}$ relação social (eu-outro) encontra-se a personalidade do ser humano, assim, chamou-se a possibilidade de encontro humano e social seu último fundamento em vida, pois o Homem possui a capacidade de dialogar.

Não é sem sentido a visão da comunidade tornar-se distinta da sociedade $^{46}$ atual, sendo que a primeira não é um mero conjunto de indivíduos, mas uma união de essência solidária entre os membros da comunidade, ao ponto da solidariedade constituir-se em um dever.

44 PIAZOLO. Solidarität, p. 72 e num sentido marxista p. 88-91 e NOGARE, Humanismo e anti-humanismo, p. 247-248; o comunismo na qualidade de ideal de uma nova sociedade, para MARX, é a abolição de toda a alienação e com isto o retorno do Homem ao seu ser social, em sua existência solidária (p. 90). Para a crítica do pensamento marxista deste aspecto da essência social do Homem, PIAZOLO. Solidarität, p. 91-93.

45 PIAZOLO. Solidarität, p. 72-73 e 198-200.

46 PIAZOLO. Solidarität, p. 101(e nota 6)-102 e 120. 
$\mathrm{Na}$ comunidade as relações sociais são duradouras e possuem um fim comum, ou seja, o membro da comunidade objetiva o mesmo que toda a comunidade. Por isso, o diálogo nas sociedades possui maior complexidade e, nem sempre, os envolvidos - "dialogantes" - partem de aspectos comuns; na comunidade isto se torna relativamente simples pelo fato destes possuírem finalidades comuns. Isto e outros fatores de semelhança entre os indivíduos na comunidade favorecem o fortalecimento da solidariedade como princípio ${ }^{47}$.

No entanto, a solidariedade não pertence somente à comunidade se não à relação entre indivíduo e comunidade, ou seja, significa ação mútua de ambos. Assim, o que o indivíduo faz ou deixe de fazer, repercute igualmente na comunidade e o que esta faz ou deixa de fazer também repercute no indivíduo. Isto indica o envolvimento de ambos mutuamente. Do que ressalta a dupla dimensão do Homem em sociabilitas e individualitas, tendo a necessidade destas duas dimensões possuírem a mesma importância a fim de evitar desequilíbrios como: o individualismo a suprimir o lado social e o comunitarismo a oprimir o lado individual. Os elementos existenciais do ser humano estão justamente nisto, no indivíduo - a formar sua singularidade - e no outro - a formar a comunidade, que contribui na formação da consciência de si mesmo, dos demais e do mundo. Indivíduo e comunidade possuem sua relação calcada na solidariedade, na ordem mútua e na independência. $O$ relacionamento mútuo e a (co)responsabilidade são aperfeiçoados pelo princípio da solidariedade, pois as duas dimensões ordenamse, necessitam-se e defendem-se reciprocamente. Destarte, nem a comunidade está a serviço somente do indivíduo, nem o indivíduo a tem como objetivo exclusivo ${ }^{48}$.

\footnotetext{
47 PIAZOLO. Solidarität, p. 73-75.

48 PIAZOLO. Solidarität, p. 75-76.
} 


\section{Solidariedade trans...}

Isso também se projeta no cenário internacional com a formação dos blocos de Estados (econômicos, culturais, sociais...), mas principalmente com sua transformação em comunidades regionalcontinentais ou mundiais que envolvem todas as esferas da vida social, não só a econômica (embora essa, na grande maioria, se não na totalidade, dos casos prevaleça como o ponto central da união).

Aformação regionalé precisolevarem consideraçãoa solidariedade entre os povos e os Estados, para que se possam igualar as condições político-econômicas e sócio-jurídicas entre os membros da união ou, pelo menos, melhorar a situação dos membros desfavorecidos. Como no Estado, as desigualdades entre os membros (cidadãos/indivíduos) precisam ser as menores possíveis/admissíveis, pois as desigualdades radicalizadas podem, como num Estado federal ou regionalizado, levar a sua dissolução. Não se trata somente dos aspectos econômicos, mas de todos aqueles que causam conflitos, corrosão das estruturas e são ameaças para a solidificação da integração. A União Européia $(U E)^{49}$ é o exemplo - até o momento - mais bem sucedido (talvez, melhor dizer, avançado) desta integração interestatal. A concepção de solidariedade na UE possui uma importante função na consolidação dos vínculos entre os Estados como na realização da união como um ideal a ser concretizado, pois ela desenvolve um papel importante na conjunção de fatores como a economia, a política e a cultura, ou seja, a solidariedade nas diretrizes européia não se restringe ao único fator ${ }^{50}$. É uma concepção que acompanha o início do projeto da comunidade européia ${ }^{51}$.

49 Considera-se o Mercosul uma união de Estados ainda não consolidada como a União Europeia.

50 Vide PIAZOLO. Solidarität, p. 188.

51 Assim é possível visualizar a solidariedade, de forma exemplificativa: Preâmbulo, Arts. $2^{\circ}$, $3^{\circ}, 3$ e $5,21^{\circ}, 24^{\circ}, 2$ e 3 e $31^{\circ}, 1$. Tratado da União Européia. http://eur-lex.europa.eu/ LexUriServ/LexUriServ.do?uri=OJ:C:2010:083:0013:0046:PT:PDF. Acesso em 6/04/2010; Preâmbulo, Arts. $67^{\circ}, 2,80^{\circ}, 122^{\circ}, 1,194^{\circ}, 1$, Título VII (Clausula de Solidariedade), Art. 
A tentativa de integração não permanece somente no âmbito nacional e regional, ela faz parte de um projeto mundial de congregação global das nações. Isto ocorre - pretende-se que ocorra, ao menos! - por intermédio das organizações mundiais como a Organização das Nações Unidas (ONU) ${ }^{52}$. Todos os Estados acolhedores desta ideia possuem um acento e participam desta estrutura abarcadora da esfera global em cooperação (Art. 1, 3, da Carta das Nações Unidas).

Assim, como os Estados federais e os blocos regionais, a união mundial é um projeto de cunho cosmopolita, pois em todas estas esferas encontram-se os diferentes e exige-se respeito e tolerância com as diferenças.

A solidariedade entre os Estados é uma formulação de direito internacional advinda do direito dos povos (Völkerrecht). Deve surgir ou existe a união de no mínimo dois sujeitos de Völkerrecht, que não deve se basear somente no interesse e nos contratos, como se compreendia a doutrina do Völkerrecht no Século XIX - em que o egocentrismo estatal era um valor inviolável e o direito internacional estava a ele vinculado porém sobre o fundamento de valor comum e de representação de todos.

$51222^{\circ}$, 1e 3. Tratado sobre o Funcionamento da União Européia. http://eur-lex.europa.eu/ LexUriServ/LexUriServ.do?uri=OJ:C:2010:083:0047:0200:PT:PDF. Acesso em 6/04/2010; Preâmbulo, Título IV (Solidariedade). Carta dos Direitos Fundamentais da União Européia. http://eur-lex.europa.eu/LexUriServ/LexUriServ.do?uri=OJ:C:2010:083:0389:0403:PT:PDF. Acesso em 6/04/2010. Além destes documentos principais da UE é possível encontrar muitos outros dispositivos legais que invocam a solidariedade, logo, tem-se a análise disto em PIAZOLO. Solidarität, p. 207-568.

52 SAUER estrutura a sua tese de solidariedade internacional como Direito com base na ideia da ONU. Destarte, os Estados participantes da ONU criam uma interdependência social abarcadora do auxílio mútuo na zona comum de atuação desta organização internacional. Logo, as normativas dela não podem ser consideradas proposições legislativas, mas normas obrigatórias a todos os membros, principalmente, no condizente à paz, à dignidade humana, aos Direitos Humanos, à ajuda humanitária e outros valores propugnados pelas ONU; com isto, somente a solidariedade entre os Estados membros pode manter a ONU como uma organização atuante, pois se tratam de Estados soberanos e independentes em sua jurisdição interna e interdependente solidariamente quando se trata da jurisdição interna da ONU. Detalhes em SAUER, Ernst. Souveränität und Solidarität. Göttingen: Musterschmidt, 1954, p. 116-130. Vide HONDRICH, Karl Otto und KOCH-ARZBERGER, Claudia. Solidarität in der modernen Gesellschaft. Frankfurt am Main: Fischer, 1992, p. 24. 
Ela se apresenta como uma categoria interestatal, como um princípio no Völkerrecht de aplicação e resulta de consequências políticas. No Século XIX a solidariedade estava marcada nos contratos ou pactos construídos pelas coordenadas teóricas do direito positivo e sua prática encontrava-se nestas condições. No Século XX começou a se visualizar a comunidade internacional, principalmente, com a fundação da ONU conjuntamente com seus objetivos em que a solidariedade encontra-se como exigência implícita para manter a paz, a segurança, as relações de amizades entre as nações, realizar cooperação internacional em relação à solução de problemas internacionais de caráter econômico, cultural, social e humanitário, além de desenvolver e estimular o respeito aos Direitos Humanos sem se fazer distinções de raça, de sexo, de idioma ou de religião. Porém, destaca-se a centralização da ONU na conjugação dos esforços das nações com o objetivo de alcançar propósitos comuns (Art. 1, 1, 2, 3 e 4, da CNU). Trata-se de uma reação à violência da Segunda Guerra Mundial, na esperança de evitar a repetição de igual ou maior tragédia ${ }^{53}$.

A solidariedade (inter)estatal ocorre quando distintos Estados munem-se de valores comuns e representações jurídicas semelhantes no sentido de mútua relação e agem em cooperação para concretizar o objetivo em tela.

Não ocorre, com isto, a perda da soberania, mas a manifestação da voluntariedade de assumir contratualmente um compromisso de auxílio mútuo. Ela ultrapassa o simples interesse, e contratos de cooperação em organizações internacionais, assentam-se atrás de condições que se impõem aos Estados membros e à união dos Estados. Esta solidariedade mútua em interdependência deixou aparecer princípios fundamentais comuns à comunidade internacional e a fundamentar a proteção dos princípios denominados de competência de organizações internacionais, a formar um esforço intensivo de trabalho conjunto. Esta cooperação

53 PIAZOLO. Solidarität, p. 129, 131 e 133-134 e CNU. http://www.un.org/es/documents/ chapter1.shtml. Acesso em: 15/03/2010. 
altera aos poucos a consciência de responsabilização dos Estados pela segurança em relação ao futuro. Por meio desta coordenação, a interdependência, foi introduzida na ordem jurídica internacional, o componente de solidariedade entre os Estados. Essa solidariedade não é simples cooperação de acordos bilaterais ou multilaterais, mas a expressão de compromisso com um mundo comum ${ }^{54}$.

Atualmente encontram-se situações complexas que necessitam de uma atuação solidária entre os Estados, seja ou não capitaneada por alguma organização internacional. Assim, a violação dos Direitos Humanos, o problema ecológico e a diferença de desenvolvimento econômico entre o sul e o norte e do leste e do oeste e o problema da migração das populações pobres em direção aos países economicamente desenvolvidos ${ }^{55}$.

Estes problemas são de desigualdades internacionais ${ }^{56}$ que se configuram em um desafio de solidariedade e de tolerância perante os Estados diretamente envolvidos, mas também é preciso compreender que os demais Estados estão indiretamente envolvidos e que não existem mais entes estatais isentos de interferirem com colaborações para amenizar ou resolver estes e outros problemas. A solidariedade, ainda mais em grau mundial, é difícil, vagarosa e complexa de ser construída ${ }^{57}$.

\footnotetext{
54 PIAZOLO. Solidarität, p. 136.

55 Vide HONDRICH und KOCH-ARZBERGER. Solidarität in der modernen Gesellschaft, p. 100-105.

56 Vide HONDRICH und KOCH-ARZBERGER. Solidarität in der modernen Gesellschaft, p. 89-99.

57 Vide HONDRICH und KOCH-ARZBERGER. Solidarität in der modernen Gesellschaft, $p$. 80-89.
} 
Em todas as esferas a solidariedade precisa estar ligada a algum princípio, pois sua forma isolada não possui características jurídicas. Assim, ela compõe a construção e a aplicação de outros princípios e institutos jurídicos. Ela, aplicada de forma isolada, pode descambar para o solidarismo tendendo a ser uma justificativa para algum tipo de doutrinação cristã ou não.

Ao chegar a este ponto rompe-se com sua concepção principal, de criar a ligação entre os indivíduos livres e iguais. Destarte, a solidariedade pode ser encontrada com o princípio federalista, na subsidiariedade ${ }^{58}$, na estruturação das finanças, no princípio democrático, na união entre os Estados.

Por meio da estrutura da solidariedade estabelece-se a relação do Estado com a sociedade e o indivíduo com a marca da liberdade e da comunidade. A partir disto podem ocorrer diversas relações como entre indivíduos singulares de maneira horizontal, entre Estados ou povos como princípio de cooperação horizontalmente, no sentido da norma

58 O princípio da subsidiariedade possui semelhança com o princípio da solidariedade por possibilitar a continuação ou realizar a tarefa de outro ente de maneira coordenada e a somar com a atividade do outro. A subsidiriedade também é aplicada em outras relações. Ela descreve a construção da sociedade e do Estado de baixo para cima a transmitir a imagem do círculo social, revelando a organização e o juízo de valor, desde a unidade menor até a maior unidade (por exemplo: unidade de trabalhadores). A subsidiariedade nem sempre necessita originar-se da competência-da competência, ela pode estar contida na ajuda entre os membros da mesma unidade ou de unidades distintas, porém sem ter um vínculo de competência, constituindo assim a ajuda - no primeiro caso - e a auto-ajuda no segundo. O princípio da subsidiariedade apresenta dois lados: o positivo e o negativo. O primeiro, a comunidade presta aos seus membros auxílio; o negativo é o reverso, ou seja, a comunidade nada permite fazer, o que seria contrário do auxílio. O princípio da subsidiariedade apresenta, fundamentalmente, uma tendência à descentralização e uma correção no coletivismo ao proteger o indivíduo diante da tutela, no qual o coletivo tem uma autorização como o indivíduo, numa relação de coordenação entre os dois a determinar o princípio da solidariedade, de forma a proporcionar a ajuda necessária. Esta compreensão leva a subsidiariedade sempre como um ato de solidariedade. Logo, o princípio de solidariedade pode ser considerado um princípio de ordenador e o de subsidiariedade de competência. Os dois devem ser realizados juntos e as responsabilidades divididas conforme suas origens. A consequência negativa a ser evitada esta na atribuição e assunção de responsabilidade a quem não a teria. PIAZOLO. Solidarität, p. 82-84. HONDRICH und KOCH-ARZBERGER. Solidarität in der modernen Gesellschaft, p. 11-12. 
jurídica verticalmente entre os cidadãos ordenados em subdivisões regionais, estatais ou supranacionais. A solidariedade em termos de concepção e de âmbito depende de cada caso e da imagem feita pelo Homem no respeitante ao seu núcleo e essência, ou seja, a variação dos seus critérios determinará o seu sentido - como: condições de sua constituição, conteúdo, objetivo, nível, disseminação $[\ldots]^{59}$.

Em todas estas esferas - nacional, regional e mundial - exigese a solidariedade como força de convergência à união. É preciso o esforço de abdicar de determinados interesses particulares e acolher os interesses comuns ou interesses da humanidade (como os valores expressos nos Direitos Humanos) ${ }^{60}$ no sentido de efetivá-los.

Além de servir de ajuda mútua, a solidariedade reduz indiferenças e conflitos, é uma atitude positiva em relação à tolerância e compositora de uma ordem e um bem comum. Nestes contextos, a solidariedade assimilará a função de compor a interação entre os diferentes, sem que cada indivíduo tenha que se submeter ao outro nem abdicar da sua particularidade individual e cultural ${ }^{61}$ - dentro da perspectiva da dignidade humana. Ela se constitui na possibilidade de todos os Homens serem reconhecidos como cidadãos do mundo em qualquer local e possuírem a Terra como sua morada, sem, no entanto, extinguir a diversidade cultural, pois ela enriquece a Humanidade e mantém a individualidade de cada um. Sem tal predisposição solidária, a união (nacional, regional e mundial) como um todo se enfraquece e corre o risco de se dissolver. Logo, não se trata de um bem comum social (redundância), mas de um

\footnotetext{
59 PIAZOLO. Solidarität, p. 22-23.

60 SAUER. Souveränität und Solidarität, p. 93-95.

61 Isto equivale ao respeito e a manutenção das soberanias dos Estados, assim tem-se a necessidade, como fundamento, de um pensamento de cooperação e integração para formar e concretizar o interesse comum da humanidade e erguer um sistema de pacífico de organização dos Estados. Isto foi um projeto de muitos teóricos, alguns deles: Pierre Dubois, Georg v. Podebrad, Emeric Cruce, William Penn, Abbé de Saint-Pierre, Immanuel Kant, William Ladd, Jeremy Bentham, James Lorimer, C. Blintschli, Pasquale Fiore e Walter Schücking. SAUER. Souveränität und Solidarität, p. 57-58.
} 
bem comum solidário, intermediado pelas éticas individual e social e estabelecido entre o individualismo e o coletivismo ${ }^{62}$.

\section{Assim, concluindo temporariamente...}

A abertura para o diferente e para a pluralidade é condição fundamental de viabilidade adaptativa às novas condições mundiais. $\mathrm{O}$ desenvolvimento da individualidade e da coletividade em isolamento não é mais possível de ser pensado. Sem a cogitação da diversidade o Estado não mais se mantém em termos humanitários, embora tendências sociais proporcionadas pelos avanços tecnológicos viabilizem a permanência do indivíduo, sem a necessidade de sair, no lar. Ainda que essa tendência favoreça ao isolamento, de uma forma ou de outra é incontornável a interação com outro indivíduo.

A coabitação do mesmo e único mundo é característica do ser humano e suas condições naturais. Todos os indivíduos pertencem ao e transitam no meio ambiente e dele retiram os recursos para sobreviverem. Por isso, um meio ambiente saudável e equilibrado é imprescindível e, assim, são necessárias ações solidárias para enfrentar o problema ambiental com a finalidade de evitar ainda mais danos e recuperar, o que é possível, as áreas degradadas.

Atualmente ao falar de república e de solidariedade não se pode deixar de lado o aspecto internacional ausente da perspectiva tradicional, ou seja, ele se tornar mais urgente do que o nacional, pois no aspecto interno existe um mínimo de solidariedade, mesmo que seja aquela advinda da identificação de um núcleo comum, a nação. No internacional o que está em destaque é a diferença e não a unidade. Isto é um fator de desestabilização. 
A solidariedade surge como elemento de ligação entre os Estados formando uma "Weltrepublik", mesmo que de forma precária. A Organização das Nações Unidas (ONU) é um gérmen ordenador de uma futura república mundial, pois nela as relações são horizontais, de determinada forma ou formalmente, muitas vezes, e o mútuo respeito e a cooperação devem estar sempre orientando as relações dentro do organismo. Mas isso não é válido somente nela, mas fora dela, nas relações de Estado-Estado não pode ser diferente.

As orientações republicanas, favoráveis a aceitar as diferenças, e as da solidariedade, favoráveis a conjugar as diferenças, servem determinantemente para fortalecer o projeto de união global e de combate à degeneração, em algum "canto" do mundo do ser humano.

E, o sentido aqui pretendido construir, precisa informar o significado do constitucionalismo contemporâneo e a atuação jurídica, em particular no âmbito da jurisdição constitucional, tão em voga contemporaneamente, indicando a resposta correta para estes princípios informadores das Cartas Políticas do nomeado neoconstitucionalismo.

\section{Referências}

AGRA, Walber de Moura. Republicanismo. Porto Alegre: Livraria do Advogado, 2005.

ALIGHIERI, Dante. Divina comédia: inferno. Tradução Italo Eugenio Mauro. São Paulo: Ed. 34, 1998.

ALIGHIERI, Dante. Divina comédia: paraíso. Tradução Italo Eugenio Mauro. São Paulo: Ed. 34, 1998.

ARENDT, Hannah. A condição humana. Tradução Roberto Raposo. 10. ed. Rio de Janeiro: Forense Universitária, 2003.

BOLZAN DE MORAIS, Jose Luis. A subjetividade do tempo: perspectivas transdisciplinares do direito e da democracia. Porto Alegre: Livraria do Advogado, 1996. 
COMPARATO, Fábio Konder. A afirmação histórica dos direitos humanos. 2. ed. São Paulo: Saraiva, 2001.

DELOGU, Antonio. Repubblica e civiche virtù. In: LEZIONI per la repubblica: la festa è tornata in città. A cura di Maurizio Viroli. Reggio Emilia: Diabasis, 2001. p. 41-50.

ELIAS, Norbert. A condição humana. Tradução Manuel Loureiro. Lisboa: Difel, 1991.

ELIAS, Norbert. O processo civilizador: formação do Estado e civilização. Tradução Ruy Jungmann. Rio de Janeiro: Zahar, 1993. v. 2.

FAZERES, António. Esboço de uma fenomenologia da liberdade. Phainomenon, Lisboa: Colibri, n. 1, p. 63-78, 2000.

FROMM, Erich. Análise do homem. Tradução Octavio Alves Velho. 9. ed. Rio de Janeiro: Zahar, 1974.

HONDRICH, Karl Otto; KOCH-ARZBERGER, Claudia. Solidarität in der modernen Gesellschaft. Frankfurt am Main: Fischer, 1992.

JASPERS, Karl. Iniciação filosófica. Tradução Manuela Pinto dos Santos. 6. ed. Lisboa: Guimarães \& C. A, [1999].

JELLAMO, Anna. Interpretazione del bene comune. Saggio su Thomas H. Green. Milano: Giuffrè, 1993.

NOGARE, Pedro Dalle. Humanismo e anti-humanismo: introdução à antropologia filosófica. 12. ed. Petrópolis: Vozes, 1990.

ORTEGA Y GASSET, José. O homem e a gente: inter-comunicação humana. Tradução J. Carlos Lisboa. 2. ed. Rio de Janeiro: Livro IberoAmericano, 1973.

PIAZOLO, Michael. Solidarität. Deutungen zu einem Leitprinzip der Europäischen Union. Würzburg: Ergon, 2004.

SAUER, Ernst. Souveränität und Solidarität. Göttingen: Musterschmidt, 1954. 
SCHACHTSCHNEIDER, Karl Albrecht. Res publica res populi. Grundlegung einer Allgemeinen Republiklehre. Ein Beitrag zur Freiheits-, Rechts- und staatslehre. Berlin: Duncker \& Humblot, 1994.

SÓFOCLES. Antígona. Tradução Donaldo Schüler. Porto Alegre: L\&PM, 2006.

VON WEIZSÄCKER, Carl Friedrich. Der garten des Menschlichen. Beiträge zur geschichtlichen Anthropologie. Müchen/Wien: Carl Hanser, 1977.

ZOLL, Rainer. Was ist solidarität heute? Frankfurt am Main: Suhrkamp, 2000.

Recebido em: 09/02/2011

Avaliado em: 14/04/2011

Aprovado para publicação em: 19/04/2011 